\title{
ENSINO-APRENDIZAGEM: UMA INTERAÇÃO ENTRE DOIS PROCESSOS COMPORTAMENTAIS
}

\author{
TEACHING AND LEARNING: AN INTERACTION BETWEEN TWO BEHAVIOURAL PROCESSES
}

\author{
Olga Mitsue Kubo ${ }^{1}$ \\ Sílvio Paulo Botomé
}

\begin{abstract}
RESUMO
O processo ensino-aprendizagem é um nome para um complexo sistema de interações comportamentais entre professores e alunos. Mais do que "ensino" e "aprendizagem", como se fossem processos independentes da ação humana, há os processos comportamentais que recebem o nome de "ensinar" e de "aprender". Processos constituídos por comportamentos complexos e difíceis de perceber. Principalmente por serem constituídos por múltiplos componentes em interação. Os próprios comportamentos são passíveis de percepção e de definição científica a partir da identificação dos seus componentes e das interações que estabelecem entre si, os quais constituem os fenômenos que recebem os nomes de "ensinar" e de "aprender". A interdependência dos dois conceitos é fundamental para entender o que acontece sob esses nomes. Sua percepção e entendimento constitui algo crucial para o desenvolvimento de qualquer trabalho de aprendizagem, de educação ou de ensino. Como identificar esses componentes? Como caracterizar as relações entre eles? Como ver o processo "ensino-aprendizagem"? Neste texto é apresentado um exame desse processo, à luz dos conceitos oriundos da Análise do Comportamento, localizando suas possíveis contribuições para o desenvolvimento da Educação em relação a experiências de grande valor que nasceram e se desenvolveram no País, quase sem conhecimento da maioria dos que o constituem e de muitos que trabalham em Educação.
\end{abstract}

Palavras-chave: Ensino programado. Ensino-aprendiza-gem. Análise do comportamento "ensinar". Análise do comportamento "aprender". Ensino personalizado.

\begin{abstract}
The learning-teaching process is a name that is given to a complex system of behavioural interactions between teachers and pupils. Apart from just "teaching" and "learning", as if these were processes independent of human activities, there are also behavioural processes that are referred to as "teaching" and "learning". They are processes comprised of behaviours that are complex and difficult to perceive, principally due to their being comprised of multiple interacting components. The very behaviours themselves are subject to perception and scientific definition based on the identification of their components and the interactions they establish between themselves and which are given the names of "teaching" and "learning". The interdependence of the two concepts is fundamental in order to understand what happens under each of these names. The perception and understanding of them is crucial for the development of any learning, education or teaching activity. How can these components be identified? How can the relationships between them be characterised? How can the "teaching-learning" process be seen? This article presents an examination of this process, in the light of the concepts arising from the Analysis of Behaviour, locating its possible contributions to the development of Education in relation to experiences of great value which originated and have been developed in Brazil, almost unknown to the majority of those that comprise them and to many who work in Education.
\end{abstract}

Key words: Scheduled teaching. Teaching-learning. Analysis of the behaviour of "teaching". Personalised teaching.

\footnotetext{
${ }^{1}$ Departamento de Psicologia da Universidade Federal de Santa Catarina. Caixa Postal 476 - 88010-970 - Florianópolis, SC - email: ok@cfh.ufsc.br.

${ }^{2}$ Departamento de Psicologia da Universidade Federal de Santa Catarina. Caixa Postal 476 - 88010-970 - Florianópolis, SC.
} 
A década de 1960 teve muitos eventos marcantes no Brasil. Eventos que deixaram lesões profundas no País. Entre elas está a redução das possibilidades de desenvolvimento de duas contribuições importantes no âmbito da Educação. Uma dessas contribuições foi a de Paulo Freire, com seu Método de Alfabetização de Adultos, que teve repercussões e desdobramentos em vários países do mundo e ficou relativamente desconhecido entre os próprios brasileiros. Outra contribuição, esta mais desconhecida, foram os trabalhos - de pesquisa e de intervenção - desenvolvidos sob a orientação de Carolina M. Bori, relacionados ao que ficou nomeado por Programação de Condições de Ensino.

As contribuições de Paulo Freire foram muito mais longe do que um método de ensino, ou do que uma técnica de alfabetização, embora isso seja percebido por poucos. Elas trouxeram consigo proposições sobre o papel do conhecimento no processo de ensinar e sobre a "realidade de inserção" da pessoa como parte da matéria-prima - talvez a mais importante - de onde derivar o que ensinar aos alunos e recurso ou referencial fundamental para constituir as decisões relacionadas a como ensinar. Nos textos de Paulo Freire (por exemplo, 1968, 1971, 1975, 1976) está presente uma concepção sobre como fazer a mediação entre conhecimento e a relação da pessoa com a sua realidade de inserção, sua vida concreta, fora dos limites temporais e geográficos das condições de ensino. $E$ isso, como contribuição importante para a educação, vai além do ensino relacionado à alfabetização de adultos, ou do ensino de $1^{\circ}$ e $2^{\circ}$ graus. Na obra de Paulo Freire, porém, os processos básicos dessa mediação e desse ensino nem sempre aparecem com uma formulação clara ou completa. O que torna a todos os que estudam e pesquisam os processos de ensinar e de aprender mais responsáveis ainda pelo conhecimento relacionado ao que Paulo Freire trouxe como contribuição. Principalmente no que diz respeito à demonstração do que acontece no método proposto por Paulo Freire e o que, nesse método, faz com que aconteça uma diferença nos processos de aprender e de ensinar. Não com procedimentos de especulação ou de defesa racional ou ideológica de uma contribuição lesada por um sistema de governo e pelas circunstâncias sociais e políticas que o País viveu nas décadas de 1960 a 1990, mas com demonstrações cuidadosas e rigorosas sobre quais são os processos que efetivamente ocorrem quando é usado o método proposto por Paulo Freire.

As contribuições de Carolina M. Bori nasceram com seu trabalho voltado para tornar o ensino mais científico e mais relevante a partir das descobertas da Ciência, particularmente da Psicologia, que surgiram na segunda metade do Século XX. No começo da década de 1960, Carolina M. Bori começara a testar, junto com outras pessoas, procedimentos que levassem o aluno a ser o centro do trabalho de ensino. Com as experiências iniciais feitas na Universidade de São Paulo, Carolina M. Bori e Rodolfo Azzi, com mais dois professores americanos (um deles era Fred S. Keller), iniciaram a proposição de uma maneira de ensinar Psicologia na nova Universidade de Brasília, quando iniciava a década de 1960. O trabalho de Carolina M. Bori e seus colegas visava desenvolver um ensino que fosse apoiado no processo de aprendizagem do aluno como centro de referência do trabalho de ensino. Esse trabalho derivava suas características iniciais das descobertas feitas na Psicologia sobre como ocorre e se desenvolve o comportamento dos organismos. Os princípios básicos eram: o ensino deveria ser definido pela atuação do aluno (e não pela do professor); a aprendizagem deveria ser feita em etapas pequenas, de acordo com as características do aluno e de suas possibilidades de aprendizagem; o aluno deveria poder prosseguir (demorando ou tendo mais ou diferentes condições) no curso conforme ocorresse sua aprendizagem; a cada aprendizagem, em lugar de notas, o aluno deveria ter conseqüências informativas, tanto técnicas como sociais, conforme seu desempenho; e, finalmente, os processos de aprendizagem dos alunos e os procedimentos do professor deveriam ser objeto de estudo constante e no próprio curso, de forma a fornecer conhecimento para aperfeiçoamento, não apenas das técnicas mas também dos conceitos fundamentais envolvidos nos processos de ensinar e de aprender. O início desse trabalho está relatado, em parte no texto "Adeus, mestre!" de Fred S. Keller, apresentado em uma conferência nos Estados Unidos em 1967 e publicado, no Brasil, na revista Ciência e Cultura (Keller, 1972) e por Kerbauy (1983), que organizou um livro com vários textos do professor Fred S. Keller. 
No Brasil, mal começara o trabalho na Universidade de Brasília, houve uma demissão de cerca de 200 professores, entre os quais o grupo que, na Psicologia, começava o trabalho de desenvolvimento do que seria, mais tarde, conhecido como Ensino Personalizado, Ensino Individualizado ou Sistema de Ensino Personalizado. Ou, ainda mais tarde, como Ensino Programado Individualizado, em alguns lugares do País. A experiência, precocemente interrompida, gerou um conhecimento que os professores americanos, que dela fizeram parte, procuraram desenvolver, ao voltar a suas universidades. E, em vários países, ela prosperou e foi utilizada sob os mais diversos nomes, em formas e graus variados, conforme a cultura onde foi realizada ou conforme as características dos usuários. Ficou, porém, uma tendência a considerar o que havia sido feito, um pouco ao gosto de suas respectivas culturas, como uma "técnica" (ou um "método", na preferência de alguns) de ensino, constituída por uma "pacote de critérios e de procedimentos". Sherman e Ruskin (1978), por exemplo, quase duas décadas depois que a experiência havia começado no Brasil, apresentavam o Sistema Personalizado de Ensino como uma série de procedimentos, a serem realizados em etapas, que não diferiam do que havia sido feito no início da década de 1960, no Brasil.

Proliferou, ao mesmo tempo, uma literatura em relação a objetivos de ensino, a definições e técnicas de formulação de objetivos e a como proceder para fazer "ensino programado". No Brasil, foram publicados, com um pouco de atraso e com características de "modismo", livros (acentuadamente, traduções de livros americanos) sobre objetivos "comportamentais" (por exemplo: Steves, 1968; Wheeler e Fox, 1973; Vargas, 1974; Mager, 1976, 1977a, 1977b; Mager e Pipe, 1976; Popham e Baker, 1976a, 1976b e 1976c). Houve, na mesma época, preocupação, nos meios educacionais, com uma categorização de objetivos (domínio afetivo, motor, intelectual), explorando a taxonomia de Bloom e colaboradores (por exemplo, Bloom, Englehart, Furts, Hill e Krathwohl, 1956). Em 1974, Mechner, que já estava com vários trabalhos sendo feitos no Brasil, publica "Análise comportamental de tarefas" e contribui para um trabalho que estava sendo feito pela Fundação CENAFOR, em São Paulo, em relação a ensino programado para cursos profissionalizantes no País. Também proliferaram críticas e avaliações relacionadas a esse tipo de trabalho e ao que recebeu o nome de "tecnologia de ensino" e de "tecnologia comportamental no ensino", alertando para os riscos e problemas envolvidos com o uso dessa tecnologia no sistema social existente (Nidelcoff, 1974; Posner e Strike, 1975; Parra, 1978; Freitas, 1979). O uso dos conceitos - alguns muito equivocadamente utilizados - passou a ser bastante amplo, embora nem sempre correspondessem ao mesmo significado para seus diferentes usuários.

Carolina M. Bori, desde a década de 1960, trabalhou não apenas com o uso da tecnologia relacionada a esses procedimentos mas, principalmente, com a investigação científica sobre o uso dessa tecnologia e sobre os processos e conceitos básicos envolvidos com essa tecnologia e com o conhecimento relacionado a ela. Principalmente o conhecimento derivado da Análise Experimental do Comportamento, recebida com muito preconceito no Brasil e com seu estudo e desenvolvimento limitado a alguns centros de pesquisa, em geral em alguns dos grandes centros urbanos do País. Do trabalho de Carolina Bori, surgiram centenas de programas de ensino, pesquisas e artigos, examinando diferentes aspectos e níveis dos conceitos e procedimentos relacionados ao que poderia ser reunido sob o nome de "análise, planejamento, programação, aplicação e avaliação de condições de ensino". Para Carolina M. Bori, para vários de seus orientandos, nos programas de pós-graduação em que atuou ao longo de quase quatro décadas, e para boa parte dos alunos e orientandos de seus orientandos, a experiência inicial de Brasília ficou longe, como fórmula ou formato. As descobertas e avanços foram se avolumando ao longo desse tempo, exigindo, cada vez mais, uma sistematização cuidadosa desse conhecimento. Conceitos foram revistos, reformulados, aprofundados, redefinidos, descobertos e alvo de testes e avaliações científicos em múltiplas pesquisas em diferentes áreas de conhecimento e em diversos campos de atuação profissional (ver Nale, 1997). A própria noção de "ensino programado" (ênfase na tecnologia elaborada) passou por uma mudança, surgindo a expressão "programação de ensino" (enfatizando os processos comportamentais complexos envolvidos na construção de programas de ensino). Com essa mudança, a tecnologia saiu do âmbito da "solução" e passou a ser parte do "problema" a ser conhecido, resolvido, superado etc. O que inicialmente era uma proposição de técnicas, passou a ser alvo de investigação constante e de estudo sistemático por vários pesquisadores no País, quase todos eles, encontrando, na sua origem, o trabalho, a orientação, a inspiração ou a administração da professora Carolina M. Bori. 


\section{OBJETIVOS DE ENSINO: O NÚCLEO DO PROCESSO DE ENSINAR}

Entre esses estudos e possíveis contribuições, encontra-se o conceito de objetivo de ensino e sua relação com o processo ensino-aprendizagem, principalmente a explicitação desse processo como uma relação entre comportamentos de professores e comportamentos de alunos, denominados de "ensinar" e de "aprender". O conceito "objetivo de ensino" foi objeto de exame por Botomé (1981) e a expressão "objetivo comportamental" foi substituída por "comportamentos-objetivo" a partir do exame desse autor, apoiado no esclarecimento da noção de comportamento como um conceito não redutível a algo igual às classes de respostas que um organismo apresenta, mas como a relação entre a classe de respostas de alguém e o meio (ambiente) em que essa classe de respostas é apresentada. Meio, entendido tanto como o que acontece antes da ação de um organismo - o ambiente antecedente a essa classe de respostas -, quanto o que decorre dessa ação ou existe em seguida a ela - o meio decorrente dela - (Botomé, 1981). O exame do conceito e os esclarecimentos de seu significado como relação entre as classes de respostas e o meio e não apenas como as respostas observáveis de um organismo vem sendo alvo de elaboração, desde Pavlov (texto de 1934, citado por Pessoti, 1979), que considerou legítimo o entendimento do "reflexo como relação entre agente externo e ação do organismo", e por Skinner (1931), que propôs uma definição do reflexo como "correlação entre estímulo e resposta", seguidos por vários outros autores. Staddon, 1967; Bolles, 1970; Seligman, 1970; Schick, 1971; Catania, 1973) e o próprio Skinner (1935, 1938, 1957, 1969, 1974) foram muito além do conceito de reflexo, explicitando múltiplas outras relações com o meio, destacando-se o conceito de comportamento operante, como uma relação de natureza diversa daquela dos reflexos estudados por Pavlov.

Com um entendimento do conceito de comportamento como um tipo de relação entre o que um organismo faz e o meio em que o faz, aparecem muitos problemas novos a investigar e conceitos a elaborar ou a reformular, em relação aos processos de ensinar e de aprender. $O$ conceito de objetivo de ensino e a própria percepção dos componentes desses dois processos podem ser melhor examinados e, a partir disso, possibilitarem um avanço significativo nas possibilidades de trabalhar melhor com esses dois processos.

O exame pode começar por algumas perguntas: qual a função dos objetivos de ensino no processo ensino-aprendiza-gem? quais os componentes dos comportamentos envolvidos nesse processo? em quais dos componentes se localizam os "objetivos de ensino"? de que forma os componentes desses dois processos se relacionam? o que pode ser alterado nos conceitos de ensinar e aprender a partir de uma percepção dos componentes dos comportamentos "ensinar" e "aprender"? são comportamentos esses dois processos? no que os comportamentos envolvidos neles podem auxiliar a aperfeiçoar os conceitos de ensino e de aprendizagem?

\section{OS PROCESSOS "ENSINO" E "APRENDIZAGEM”}

É freqüente o uso dos substantivos "ensino" e "aprendizagem" para fazer referência aos processos "ensinar" e "aprender". Raramente fica claro que as palavras referem-se a um "processo" e não a "coisas estáticas" ou fixas. Nem sequer pode ser dito que correspondam a dois processos independentes ou separados. Nesse sentido, é melhor usar verbos para referirse a esse processo, fundamentalmente constituído por uma interação entre dois organismos (pelo menos no caso de "ensinar", uma vez que é possível "aprender" sem um professor). Mas as perguntas importantes permanecem. O que é ensinar? O que é aprender? Como se relacionam esses dois processos? Que tipos de eventos constituem esses fenômenos? Como enxergá-los? Como produzi-los? Como interferir em suas características?

As respostas tradicionais não satisfazem. Definições como as de dicionário (ensinar é "dar instrução a", "doutrinar", "mostrar com ensinamento", "demonstrar", "instruir" etc.) são meras sinonímias ou redundâncias e não diferem muito das definições entre profissionais da Educação ("transmitir conhecimento ou conteúdo", "informar", "preparar", "dar consciência" etc.). Paulo Freire (1971) denunciou que essas expressões são compatíveis com o que define uma "concepção bancária" de educação e não permitem o desenvolvimento de uma "prática educacional" adequada. Skinner (1972) comentou que a maior parte das definições são meras ficções verbais, convenções vazias que não se referem ao que acontece e sim aos efeitos que 
o uso desses termos tem sobre os ouvintes (outro tipo de "acontecimento" diferente daquele a que se referem as palavras utilizadas). De maneira semelhante, ocorre o mesmo com o que é definido por "aprender". Expressões familiares parecem auto-evidentes, inquestionáveis ou impossíveis de explicitar de outras formas que não as já conhecidas.

A Análise do Comportamento pode contribuir para auxiliar no esclarecimento do que é o "processo ensinar-apren-der". O primeiro aspecto a considerar é que as expressões "ensinar" e "aprender" são dois verbos que se referem, respectivamente, ao que faz um professor e ao que acontece com o aluno como decorrência desse fazer do professor. A própria noção de comportamento (uma relação entre aquilo que o organismo faz e o ambiente em que o faz) já auxilia a perceber um possível caminho para examinar esse processo de interação. Parece caber, antes de qualquer outra providência, uma descrição (e não apenas uma definição) do que consiste "ensinar". Um segundo aspecto a ser levado em conta nas possibilidades de ajuda da Análise do Comportamento na elucidação do que seja "ensinar e aprender" é que o termo "ensinar" é um verbo e se refere a uma categoria de comportamentos que caracterizam o que um professor faz. Ensinar, nesse sentido, é uma atividade humana e, portanto, passível de análise comportamental.

O terceiro aspecto decorre dessa possibilidade: como analisar essa categoria de comportamentos? Se ensinar é uma categoria de comportamentos e, portanto, uma relação com o ambiente, cabe perguntar: a) quais as classes de estímulos (aspectos da situação em que a ação ocorre) envolvidas?; b) quais as classes de respostas (as ações) relacionadas a essas classes de estímulos?; c) quais suas conseqüências ou produtos (classes de estímulos conseqüentes às respostas ou aspectos das situações decorrentes dessas respostas)?

\section{O COMPORTAMENTO “ENSINAR"}

A análise pode começar pela consideração de que o mais crítico na relação com o ambiente explicitado pela palavra ensinar é o efeito do que o professor faz. E o tipo de efeito importante é a aprendizagem do aluno. Bushell (1973) considera que muitas das explicações para o fracasso da aprendizagem são apenas explicações para o fracasso do ensino. Ninguém pode afirmar que "ensinou, mas o aluno não aprendeu". Ensinar define-se por obter aprendizagem do aluno e não pela intenção (ou objetivo) do professor ou por uma descrição do que ele faz em sala de aula. A relação entre o que o professor faz e a efetiva aprendizagem do aluno é o que, mais apropriadamente, pode ser chamado de ensinar. Nesse sentido, ensinar é o nome da relação entre o que um professor faz e a aprendizagem de um aluno.

Apresentando os componentes dessa relação (desse comportamento) em um "esquema", ficará mais claro o que pode constituir o comportamento "ensinar". No Quadro 1 pode ser vista uma representação esquemática do que define a palavra ensinar ou do que pode constituir o fenômeno ou o processo ensinar. A seta é o que melhor representa o que é central na definição de "ensinar": a relação entre dois componentes de um comportamento, uma classe de respostas

Quadro 1: Representação esquemática da relação que constitui o ensino: o que o professor faz (classe de respostas) é responsável pela aprendizagem do aluno (situação conseqüente)

\begin{tabular}{|c|c|c|}
\hline & CLASSE DE RESPOSTAS & $\begin{array}{c}\text { SITUAC̃ÃO } \\
\text { CONSEQÜENTE }\end{array}$ \\
\hline AÇÕES DO & $\begin{array}{c}\text { APRENDIZAGEM DO } \\
\text { ALUNO } \\
\text { EFETIVADA }\end{array}$ \\
\hline
\end{tabular}

(que precisará ter certas características para ser) capaz de gerar um efeito ou resultado que recebe o nome de aprendizagem. Sem esse resultado ou efeito, não é apropriado dizer que um professor, ao fazer algo, ensinou. Ou então, seria necessário admitir que é apropriado dizer que um professor ensina, mesmo quando os alunos não aprendem. O conceito de ensinar tem, em seu núcleo definidor, um acontecimento necessário: a ocorrência de aprendizagem. O 
esquema do Quadro 1 é apenas a ilustração desse raciocínio, mostrando os componentes de um comportamento (ensinar), o qual, por sua vez, é representado pela seta estabelecendo a relação (de produção, nesse caso) entre os dois componentes indicados no Quadro 1.

Há, no Quadro 1, ainda, a falta de uma maior explicitação do que seja "aprendizagem efetiva" do aluno. Segundo Bushell (1973), a mudança de comportamento do aluno (alteração de suas relações com o meio) é o que, fundamentalmente, evidencia aprendizagem. Nesse sentido, há necessidade de descrever melhor os componentes do comportamento ensinar, explicitando o que caracteriza a aprendizagem. E possível aprofundar o que Bushell defende como sendo o que constitui o aspecto definidor do que é chamado por "aprendizagem", principalmente sobre o que "evidencia a ocorrência de aprendizagem". Mas isso envolve outros aspectos que exigem exames, debates e resolução de controvérsias sobre outros conceitos relacionados a esses termos como, por exemplo, "comportamento" e "mudança de comportamento". No momento, parece suficiente assinalar que o que Bushell considera sobre aprendizagem não esgota todos os aspectos do conceito e que 0 assunto pode ser aprofundado mais do que o é neste exame. Mesmo proposições de origem diversa do que a da Análise do Comportamento, concordam que não é apenas o que o aluno faz, mas suas relações com seu meio que evidenciam o que, de fato ele está produzindo de transformações nesse meio. Nesse sentido, o que aluno conseguirá fazer com seu meio é o que evidenciará a ocorrência de aprendizagem.

Também há alguns aspectos que o professor - ao "ensinar" - "leva em conta" ou "com os quais toma contato". Eles também se relacionam às suas classes de respostas (a suas ações) e precisam ser explicitados para entender melhor a relação comportamental em exame (ou o comportamento em análise). No Quadro 2, é possível ver um maior detalhamento da relação entre o que o professor faz (classes de respostas do professor) e os resultados - pelo menos, um dos tipos de resultados - que precisam ser produzidos por essas classes de respostas (eles constituem a situação subseqüente) para a relação receber, apropriadamente, o nome "ensinar". Com a presença desses componentes (com as variações que diferentes concepções podem ter a respeito de cada um dos componentes) pode ser apropriadamente dito que há ensino efetivo. Um aspecto importante a destacar é que as características das classes de respostas do professor não definem que ele ensinou. É claro que deve haver algumas classes de respostas que são melhores que outras para obter com mais eficácia o desempenho final do aprendiz sem, inclusive, Ihe ser aversivo, difícil ou desagradável. Os procedimentos do professor descritos por Keller (1972) fazem parte desse tipo de classes de respostas. E evidente que ainda é possível descobrir formas mais efetivas de ensino do que esses procedimentos. O que demonstrará sua efetividade é a relação funcional entre propriedades definidas de classes de respostas do professor com aspectos, também definidos, do que acontece com o aprendiz.

Quadro 2: Explicitação esquemática de componentes constituintes do comportamento "ensinar" para exemplificar como esses componentes constituem a relação (entre situação antecedente a uma classe de respostas, a própria classe de respostas e a situação conseqüente a essa classe de respostas), indicada pela seta

\begin{tabular}{|c|c|c|}
\hline \multicolumn{3}{|c|}{ COMPORTAMENTO DE ENSINAR } \\
\hline SITUAÇÃO ANTECEDENTE & $\begin{array}{c}\text { CLASSE DE } \\
\text { RESPOSTAS DO } \\
\text { PROFESSOR }\end{array}$ & $\begin{array}{c}\text { SITUAÇÃO } \\
\text { CONSEQÜENTE }\end{array}$ \\
\hline $\begin{array}{l}\text { - Objetivos de ensino definidos } \\
\text { (descrição do desempenho final } \\
\text { do aprendiz ou de outras } \\
\text { concepções de objetivos, do } \\
\text { professor) } \\
\text { - características dos aprendizes: } \\
\text { - capacidade de desempenho } \\
\text { inicial dos aprendizes; } \\
\text { - interesses; } \\
\text { - etc. }\end{array}$ & $\begin{array}{l}\text { Quaisquer classes de } \\
\text { respostas do professor }\end{array}$ & $\begin{array}{l}\text { - Desempenho do } \\
\text { aprendiz, de } \\
\text { acordo com } \\
\text { objetivos } \\
\text { definidos pelo } \\
\text { professor } \\
\text { - Outros } \\
\text { desempenhos do } \\
\text { aprendiz }\end{array}$ \\
\hline - matérias e condições de ensino & & \\
\hline
\end{tabular}

Também é possível especificar melhor os três componentes do que é chamado "ensinar", acrescentando aspectos, especificando mais os que estão no Quadro 2, etc. Para o exame até este ponto da argumentação, porém, parece suficiente esse nível de explicitação, 
uma vez que trata-se de explicitar uma maneira de analisar e não, pelo menos neste contexto, de esgotar a análise do comportamento de ensinar ou do conceito de ensino.

\section{OS COMPORTAMENTOS QUE DELIMITAM O "APRENDER"}

Em relação ao resultado dessas ações do professor (a "aprendizagem" ou o "aprender") pode ser feita uma análise semelhante. Neste caso, porém, o foco de interesse é o comportamento do aluno e não o do professor. Para iniciar esse exame, é preciso considerar, de imediato, o que caracteriza a relação de um organismo que "não aprendeu" a interagir com seu ambiente. Utilizando os conceitos e procedimentos que constituem instrumentos da Análise do Comportamento, é possível especificar os três componentes dessa relação: situação (classes de estímulos antecedentes), ação (classes de respostas) e resultados (classes de estímulos conseqüentes). O Quadro 3 contém uma explicitação (genérica e ainda incompleta, mas suficiente como exemplificação da análise que pode ser feita) desses três componentes do comportamento de alguém que "não aprendeu" ou que age diante de suas circunstâncias de vida de forma a não resolver as situações-problema com as quais se defronta. Os aspectos da situação com a qual o organismo (o sujeito) se defronta não necessariamente são completa ou adequadamente percebidos pelo sujeito (ou organismo) que age (que apresenta as respostas de uma classe), mas são o que constituem o meio no qual o sujeito está inserido. Percebê-los (identificá-los) e caracterizá-los faz parte do que ele precisa aprender. As classes de respostas (de ações) podem variar, como ilustra o Quadro 3, desde a repetição da mesma, pura e simplesmente, até múltiplas possibilidades de variação nas características dessas classes de respostas. As conseqüências de agir dessa forma, nessas situações, são, não só deixar o problema (a situação original) sem solução (sem mudança significativa), como também piorar o que acontece (ver a terceira coluna do Quadro 3). As relações indicadas pelas flechas constituem o que pode ser chamado de comportamento ineficaz, comportamento equivocado, comportamento inapropriado, caracterizando que o sujeito (o organismo) não está sendo capaz de apresentar classes de respostas que constituam uma outra relação com o meio, de forma a gerar conseqüências (resultados) que constituam uma alteração significativa (ou de interesse) nesse meio.

Quadro 3: Componentes do comportamento típico de um organismo que ainda "não aprendeu" e que permitem identificar o tipo de relação entre o que esse organismo faz e o ambiente em que o faz

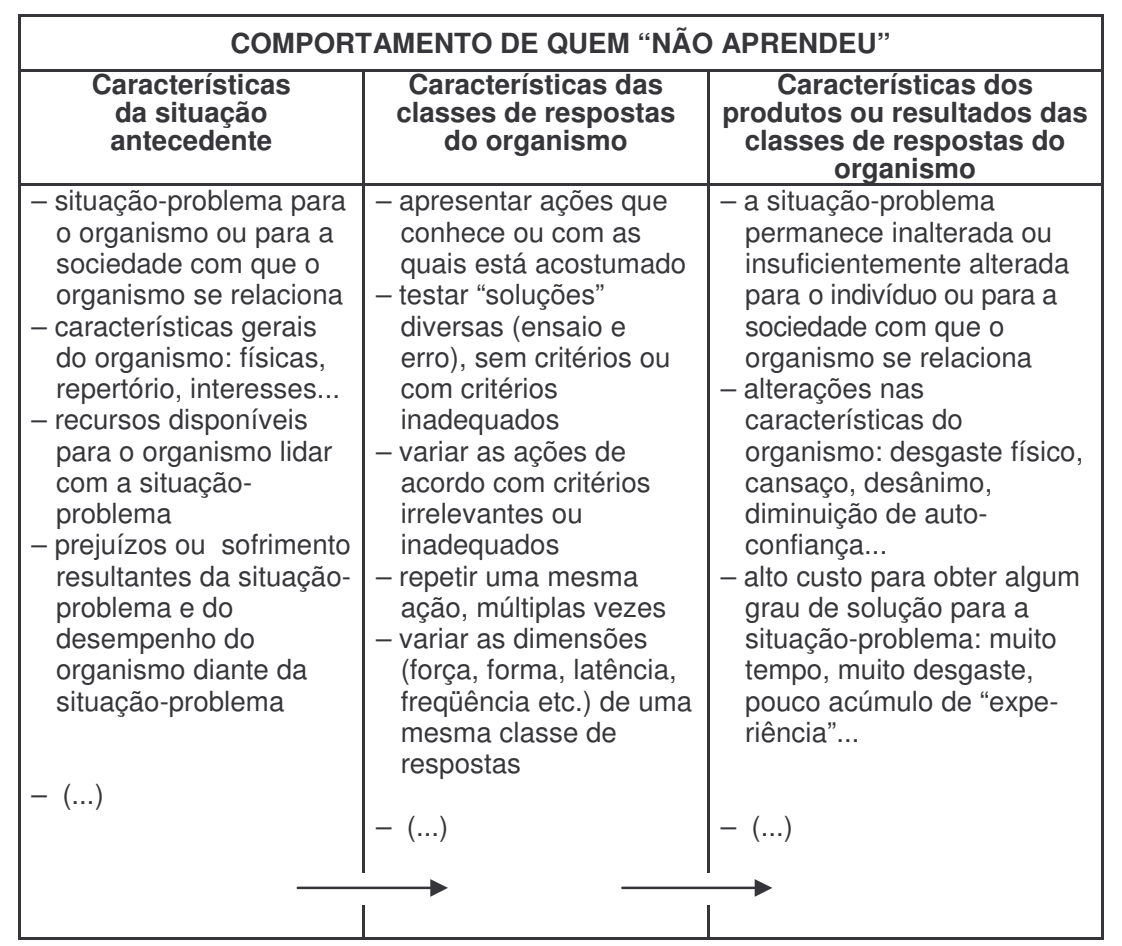

No esquema do Quadro 3, pode ser visto que a situação existente não é transformada em outra mais desejável por meio das ações do organismo. Ủma pessoa diante de situaçõesproblema (de qualquer tipo) e que age conforme está descrito nesse quadro, produzirá 
resultados, muito provavelmente, conforme os descritos na coluna da direita do mesmo quadro. Essa é a condição em que se encontram os indivíduos que, de acordo com o que é dito, "não sabem" ou "não aprenderam". Essas expressões apenas dizem que, diante de situaçõesproblema, essas pessoas tendem a agir de forma que tem muito pouca probabilidade de reduzir as dificuldades ou resolver a situação-problema (em geral, agem e, com isso, aumentam as dificuldades e problemas). Quanto mais séria for a situação-problema, mais prejuízos terá o indivíduo e os que estão envolvidos com ela. É possível imaginar, por exemplo, um profissional (de qualquer campo de atuação) agindo conforme o que está ilustrado no Quadro 3. Os prejuízos sociais decorrentes parecem óbvios. As relações (representadas pelas setas) parecem ser inadequadas para "transformar a realidade com a qual o organismo se defronta", usando expressões que se aproximam das propostas de Paulo Freire $(1975 ; 1976)$ para entender o papel da educação na vida de uma pessoa. Um processo de humanização está assentado na capacidade de uma pessoa interagir com seu meio e essa capacidade pode, exatamente, constituir o que é alvo (ou objetivo) do ensino (ou de ensinar).

É possível, também, fazer uma descrição das características dos componentes do comportamento de um indivíduo que "aprendeu". Tal indivíduo deveria, diante das mesmas situações, agir de maneira diferente (mais apropriada às características dessas situações) daquela de quem "não aprendeu". E, também, produzir resultados diferentes daqueles produzidos por este último tipo de aprendiz. No esquema do Quadro 4, é possível examinar as características dos três componentes do comportamento de quem aprendeu algo. Obviamente esses componentes do comportamento estão descritos em termos gerais e ainda podem ser complementados.

Nos componentes do comportamento (da "classe de comportamentos" é uma expressão mais adequada para denominar uma relação com o ambiente em tal nível de generalidade) que podem ser vistos no Quadro 4, é possível perceber que as características da situação antecedente (as classes de estímulos antecedentes) são as mesmas que estão apresentadas no Quadro 3. As características da "maneira de agir" (das classes de respostas) e dos "resultados" ou das mudanças produzidas (as classes de estímulos conseqüentes às classes de respostas), porém, são bem diferentes. Cada um desses dois quadros ilustra um "padrão" (ou um tipo, ou uma forma) de relação com o ambiente (padrão, tipo ou forma de comportamento) que caracteriza "não ser capaz" e "ser capaz" de lidar com as situações com as quais alguém se defronta. Onde, porém, está o "aprender", a "aprendizagem"? É possível dizer que a "aprendizagem" ou

Quadro 4: Componentes do comportamento típico de um organismo que "aprendeu" uma relação com o ambiente e que permitem identificar o tipo de relação entre o que esse organismo faz e o ambiente em que o faz

\begin{tabular}{|c|c|c|}
\hline \multicolumn{3}{|c|}{ COMPORTAMENTO DE QUEM “APRENDEU” } \\
\hline $\begin{array}{l}\text { Características da } \\
\text { situação antecedente }\end{array}$ & $\begin{array}{c}\text { Características das } \\
\text { classes de respostas } \\
\text { do organismo }\end{array}$ & $\begin{array}{l}\text { Características dos produtos } \\
\text { ou resultados das classes de } \\
\text { respostas do organismo }\end{array}$ \\
\hline $\begin{array}{l}\text { - situação-problema } \\
\text { para o organismo ou } \\
\text { para a sociedade } \\
\text { com a qual o } \\
\text { organismo se } \\
\text { relaciona } \\
\text { - características gerais } \\
\text { do organismo: físicas, } \\
\text { repertório, } \\
\text { interesses... } \\
\text { - recursos disponíveis } \\
\text { para o organismo } \\
\text { lidar com a situação- } \\
\text { problema } \\
\text { - prejuízos ou } \\
\text { sofrimento } \\
\text { resultantes da } \\
\text { situação-problema e } \\
\text { do desempenho do } \\
\text { organismo diante da } \\
\text { situação-problema } \\
\end{array}$ & $\begin{array}{l}\text { - estabelecer as } \\
\text { características do } \\
\text { problema a ser } \\
\text { resolvido } \\
\text { - explicitar alternativas } \\
\text { de solução } \\
\text { apropriadas ao } \\
\text { problema } \\
\text { - escolher qual a } \\
\text { melhor alternativa de } \\
\text { solução em função } \\
\text { de suas } \\
\text { características, dos } \\
\text { recursos disponíveis } \\
\text { e dos resultados de } \\
\text { interesse } \\
\text { - apresentar ações } \\
\text { precisas } \\
\text { correspondentes ao } \\
\text { melhor procedimento } \\
\text { para solucionar o } \\
\text { problema } \\
\text { - (. . .) }\end{array}$ & $\begin{array}{l}\text { - situação-problema resolvida } \\
\text { (desaparece ou diminui) } \\
\text { - organismo obtém resultados de } \\
\text { interesse (dos quais necessita) } \\
\text { - comunidade (ou sociedade) } \\
\text { obtém resultados de interesse } \\
\text { - pouco desgaste do organismo } \\
\text { - experiência acumulada para } \\
\text { lidar com novas situações- } \\
\text { problema (ou com a mesma) } \\
\text { - redução de prejuízos ou de } \\
\text { sofrimento } \\
\text { - aumento da probabilidade de, } \\
\text { em circunstâncias (ou } \\
\text { situações) semelhantes, } \\
\text { apresentar desempenhos } \\
\text { parecidos }\end{array}$ \\
\hline
\end{tabular}


o "aprender" é a mudança do primeiro tipo de relação com o ambiente (o comportamento analisado no Quadro 3) para o segundo tipo de relação com o ambiente (o comportamento analisado no Quadro 4).

\section{AS RELAÇÕES ENTRE ENSINAR E APRENDER}

O Quadro 5 sumariza o que está representado nos Quadros 1 a 4. Mesmo com uma mudança de linguagem (aspectos de uma situação ou

Quadro 5: Componentes das três classes de comportamentos envolvidos no processo "ensino-aprendizagem". Na parte superior, estão representados os componentes que constituem o "ensinar" (a seta indica o que é definidor desse comportamento) e, na parte inferior, a mudança que constitui a "aprendizagem" (a seta indica a alteração de uma maneira de relacionar-se com o ambiente para outra, ou a mudança do comportamento analisado no quadro 3 para 0 analisado no quadro 4)

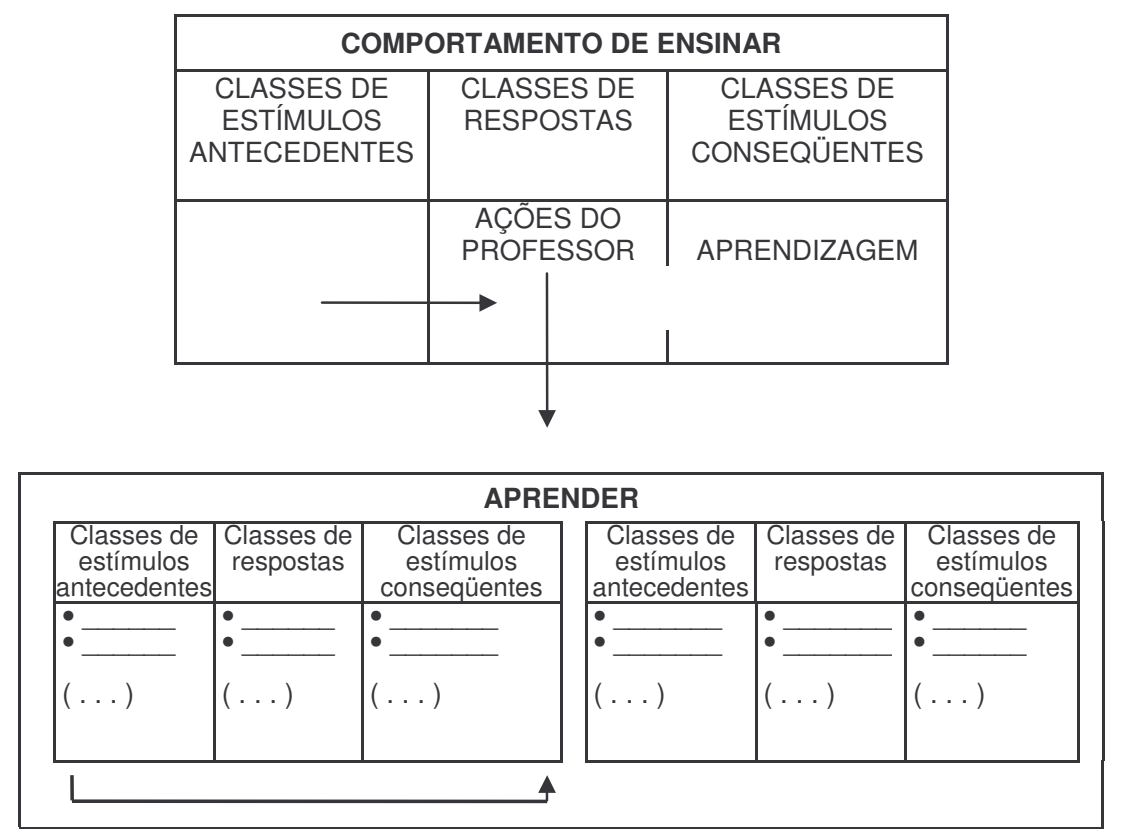

classes de estímulos antecedentes podem ser considerados como expressões equivalentes, ações ou classes de respostas também, assim como aspectos das situações resultantes, ou resultados, ou efeitos, ou classes de estímulos conseqüentes) é possível identificar o que foi examinado nos quadros 1 a 4, na composição apresentada no Quadro 5. Nele, fica mais clara a relação entre os componentes dos dois comportamentos (ou dois processos), o do professor que procura ensinar ao aluno uma maneira de relacionar-se com sua realidade (as circunstâncias) com que se defrontará na sociedade) diferente da que ele tem condições de apresentar sem um auxílio de alguém. Caso o professor não o auxilie, não ensine tal maneira de agir perante as circunstâncias com que se defrontará, o aluno provavelmente demorará muito tempo e terá um custo muito alto até descobrir como estabelecer uma relação melhor com as circunstâncias com que se defronta ou defrontará. Começam a aparecer algumas exigências que um professor precisa atender para poder realizar, de fato, um ensino, ou obter uma aprendizagem de outra pessoa. É possível prosseguir o exame dessas relações, explicitando o que, no Quadro 5, está apresentado em esquema.

Com os Quadros 1 a 5 fica mais claro porque há uma estreita e bem definida ligação entre "ensinar" e "aprender". Os dois tipos de eventos estão relacionados e são interdependentes. São, de certa forma, "duas faces da mesma moeda". No Quadro 6 são apresentados os componentes do comportamento "ensinar", integrando os vários aspectos já considerados nos Quadros 1 a 5 e explicitando-os de forma mais precisa. À esquerda, são apresentadas as características da situação com as quais deve lidar quem "ensina". Em primeiro lugar está a situação problema para o professor, que é uma relação entre o que o aluno faz e a realidade em que o faz, caracterizada por um desempenho inicial perante uma situação e que gera um determinado resultado. Sem conhecer a realidade com a qual o aluno deve estar apto a lidar, o desempenho que é capaz de apresentar e o que ele consegue obter 
(resultados) com esse desempenho, o professor corre o risco de, por ignorá-los, apenas "apresentar informações e cobrar adesão do aluno", como se "falar sobre as informações apresentadas" ou "agir de acordo com receitas dadas" fossem as grandes características definidoras do que constitui "ensinar". No Quadro 6 há exigências mais complexas para delimitar o papel do conhecimento no processo (ou no comportamento) de ensinar.

Quadro 6: Componentes do comportamento "ensinar", explicitando os "componentes dos componentes", quando estes são classes de comportamentos do aprendiz

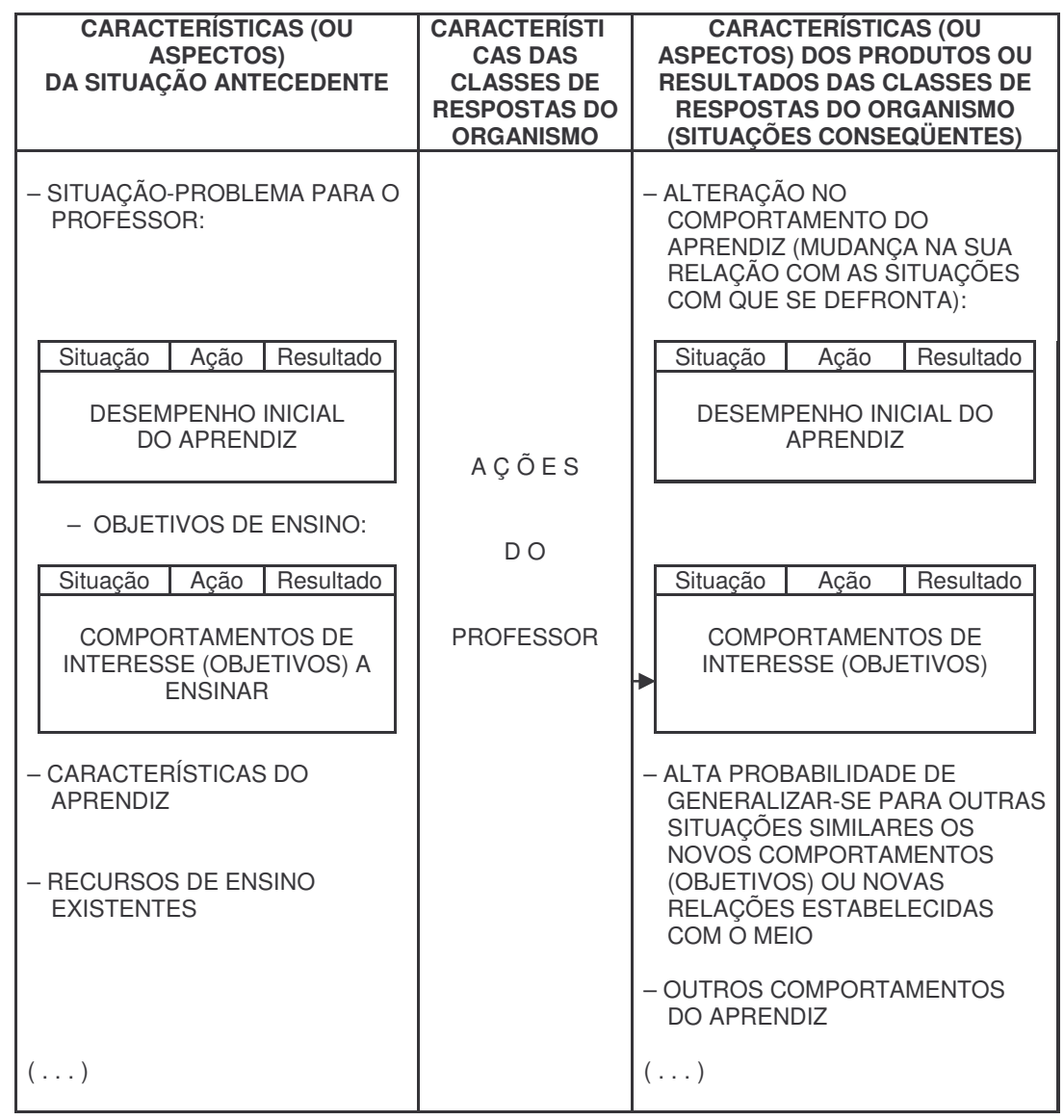

O segundo aspecto à esquerda refere-se também ao comportamento do aluno, só que ao que ele deveria estar apto a realizar quando "aprendesse" (objetivos de ensino). Novamente, é fácil notar no Quadro 6 que esses "comportamentos de interesse" (que, obviamente, devem ser importantes para a comunidade onde viverá o aluno) têm três componentes: (1) a situação-problema com a qual se defrontará, (2) o desempenho que deverá apresentar perante essa situação de forma a produzir (3) um resultado de valor (mudança na situação-problema com a qual se defronta) para a sociedade e para si próprio. Cada um desses componentes exige investigação, conhecimento e decisão por parte de quem ensina para poder compor o que constituirá seus objetivos de ensino e, como decorrência, quais procedimentos adotará para planejar e realizar o ensino ou as interações que vai desenvolver com os alunos.

O terceiro aspecto das características da situação antecedente que compõem o comportamento de ensinar é integrado pelas características do aprendiz (idade, habilidades que já desenvolveu, interesses, características físicas, biológicas etc). Elas são, também, aspectos importantes que o professor precisa levar em conta ao "ensinar". As ações do professor devem ocorrer também sob controle (influência) desses tipos de características dos alunos. São elas que orientarão a natureza de suas decisões sobre os objetivos, sobre as aprendizagens intermediárias a desenvolver para chegar a atingir tais objetivos, as estratégias, procedimentos e materiais necessários para a organização do programa de ensino, bem como o tamanho ou a complexidade de cada unidade de ensino que irá desenvolver.

Além desses três tipos de características, há os "recursos de ensino existentes" que também devem ser levados em conta pelo professor ao "ensinar". Dito de outra maneira, os recursos de ensino disponíveis também devem controlar (ou influenciar) as características das ações do professor em relação ao trabalho de ensino. Um planejamento deve superar ou ir 
além das limitações das circunstâncias existentes, mas precisa estar apoiado no que existe como ponto de partida para superá-los.

No componente "características das classes de respostas" do professor há apenas a expressão "ações do professor". Isso significa que quaisquer que forem as ações do professor, elas precisarẵo gerar os resultados de interesse (a coluna à direita no Quadro 6) para poder receber o nome de "ensino". Não se trata de dar, ao professor, receitas de conduta, mas de indicar-lhe um referencial que pode auxiliá-lo a escolher, entre muitas condutas ou procedimentos, os melhores para gerar os resultados de interesse: as aprendizagens relevantes para a vida do aluno em sua inserção na sociedade.

São os aspectos desse referencial que se encontram descritos na terceira coluna (o terceiro componente) do Quadro 6. Nela encontram-se explícitas as características dos produtos ou resultados das classes de respostas do professor. O primeiro deles é uma alteração no comportamento original do aprendiz: o desempenho inicial (inadequado ou insuficiente) desaparece ou diminui e surge um novo desempenho. Dessa forma, fica enfraquecido um tipo de relação com o ambiente e fortalecido um outro tipo de relação (fica mais provável de ocorrer uma outra maneira de agir quando se apresentar a situação-problema em exame). O aspecto importante nessa primeira característica (alteração no comportamento do aprendiz) não é o desempenho inicial, nem o desempenho final e sim a mudança de um para outro, representada pela seta no componente da direita, no Quadro 6. Quando essa mudança é produzida pela ação do professor, pode ser dito que houve ensino. Se ela ocorrer sem a intervenção de alguém, houve apenas aprendizagem (a natureza e as situações também ensinam, sem a ajuda das pessoas!).

Além dessa característica (a mudança de um comportamento inadequado, ineficaz ou irrelevante para um mais apropriado) há uma outra também muito importante na definição do que constitui o que pode ser chamado de "ensinar": aumento da probabilidade de ocorrência das novas maneiras de agir, em situações com propriedades semelhantes às da situaçãoproblema. Toda aprendizagem que ocorre nos termos em que o Quadro 6 apresenta, tem alguma probabilidade de generalizar-se, de alguma forma e em algum grau, para outras situações diferentes, em algum aspecto ou grau, daquela que foi apresentada ao aluno. Compete ao professor ter visibilidade também sobre quais generalizações - e que quantidade de cada uma - interessa como resultado do ensino. Há, em relação a essa característica, problemas e controvérsias que não vem ao caso examinar neste contexto, mas que permanecem em aberto quanto a respostas de boa qualidade para eles: quanto é possível essa generalização, em que medida é desejável, de que maneira planejá-la ou levá-la em conta no trabalho de ensinar, quais os perigos existentes etc.

Uma terceira característica desse mesmo componente é "outros comportamentos do aprendiz" (ver terceira coluna no Quadro 6). Sua variedade, significação, relevância, adequação etc., tanto quanto sua ocorrência, não foram previstos pelo professor. O que não os torna inúteis, indesejáveis ou pouco significativos. Cabe ao professor, novamente, lidar com eles como indicadores do grau e qualidade do seu "ensino". Raramente um organismo aprende, ao agir em um ambiente, apenas aquela unidade de aprendizagem que alguém programou. Obviamente isso não é, necessariamente, um prejuízo. Pelo contrário, pode ser um grande benefício para o trabalho de ensino. O que importa é o professor acompanhar o que acontece e aprender (investigar e sistematizar) com o próprio trabalho de ensino. As condições de ensino e os objetivos, principalmente quando são de boa qualidade, tendem a possibilitar outras aprendizagens em relação a eles próprios.

\section{O PROCESSO - OU CADEIA COMPORTAMENTAL - DENOMINADO "ENSINAR”}

O Quadro 6, apesar de todos esses detalhes, ainda mostra os componentes da relação (do comportamento) "ensinar" de maneira esquemática. No Quadro 7 estão apresentadas as características dos três componentes desse comportamento explicitadas de maneira mais completa e menos esquematicamente. Neste novo quadro, à esquerda podem ser observados cinco exemplos de "aspectos da realidade que o professor precisa levar em conta para desenvolver um trabalho de ensino". Cada um desses "aspectos" não é "dado ao professor"; ele próprio deve produzi-los por meio de observação (mesmo que indireta) e de descrições apropriadas para orientar suas decisões e atividades como educador. $O$ conhecimento existente e as situações que constituem a realidade dos alunos são as fontes para descobrir cada um desses aspectos e cada uma das características deles.

Na coluna central no Quadro 7 há indicações de algumas classes de ações que geram parte do que é "situação antecedente" e que orientam cada decisão do docente. As várias classes de ações apresentadas nessa coluna indicam que a "ação do professor" é, mais 
precisamente, uma cadeia de ações integradas (cada uma cria condições para ocorrer uma ação seguinte em uma complexa seqüência de classes de ações). As reticências indicam que existem elos dessa cadeia

Quadro 7: Componentes do comportamento "ensinar", explicitando características desses componentes e partes da seqüência de ações que um professor precisa apresentar para "desenvolver ensino-aprendizagem"

\begin{tabular}{|c|c|c|}
\hline \multicolumn{3}{|c|}{ COMPORTAMENTO DE ENSINAR } \\
\hline $\begin{array}{l}\text { CARACTERÍSTICAS } \\
\text { DA SITUAÇÃO } \\
\text { ANTECEDENTE }\end{array}$ & $\begin{array}{l}\text { CARACTERÍSTICAS DAS } \\
\text { CLASSES DE RESPOSTAS } \\
\text { DO ORGANISMO }\end{array}$ & $\begin{array}{l}\text { CARACTERÍSTICAS DOS } \\
\text { PRODUTOS OU DOS } \\
\text { RESULTADOS DAS } \\
\text { CLASSES DE RESPOSTAS } \\
\text { DO ORGANISMO }\end{array}$ \\
\hline $\begin{array}{l}\text { - situação-problema para o } \\
\text { organismo ou para a so- } \\
\text { ciedade com a qual o } \\
\text { organismo se relaciona } \\
\text { - características gerais do } \\
\text { organismo: físicas, } \\
\text { repertório, interesses... } \\
\text { - recursos disponíveis para o } \\
\text { organismo lidar com a } \\
\text { situação-problema } \\
\text { - prejuízos ou sofrimento } \\
\text { resultantes da situação- } \\
\text { problema e do desempe- } \\
\text { nho do organismo diante } \\
\text { da situação-problema } \\
\text { - ( . . . ) } \\
\text { - recursos de ensino } \\
\text { existentes: materiais, } \\
\text { tempo, técnicas, } \\
\text { ambientes... } \\
\text { - (...) }\end{array}$ & $\begin{array}{l}\text { - descrever as situações- } \\
\text { problema existentes nos } \\
\text { ambientes nos quais o } \\
\text { aprendiz vai atuar } \\
\text { - ( . . .) } \\
\text { - propor os comportamentos } \\
\text { significativos que deverão } \\
\text { constituir os objetivos de } \\
\text { ensino } \\
\text { - explicitar as aprendizagens } \\
\text { necessárias para a } \\
\text { consecução dos } \\
\text { comportamentos-objetivo } \\
\text { - ( . . .) } \\
\text { - dispor as condições e os } \\
\text { meios de ensino para de- } \\
\text { senvolver a aprendizagem } \\
\text { dos comportamentos-obje- } \\
\text { tivo } \\
\text { - ( . . . ) }\end{array}$ & $\begin{array}{l}\text { - "aprendiz" apto a apresentar } \\
\text { condutas para a solução das } \\
\text { situações-problema da } \\
\text { comunidade } \\
\text { - situações-problema da } \\
\text { comunidade resolvidas ou } \\
\text { atenuadas } \\
\text { - diminuição do montante de } \\
\text { problemas sociais } \\
\text { - alta probabilidade de o } \\
\text { aprendiz voltar a apresentar } \\
\text { comportamentos iguais ou } \\
\text { semelhantes perante } \\
\text { situações equivalentes ou } \\
\text { similares } \\
\text { - satisfação e auto-confiança } \\
\text { (do "aprendiz") } \\
\text { - melhoria na qualidade das } \\
\text { interações sociais na } \\
\text { comunidade } \\
\text { - ( . . ) } \\
\text { - novos comportamentos } \\
\text { (objetivos) com alta } \\
\text { probabilidade de } \\
\text { generalização } \\
\text { - ( . . . ) }\end{array}$ \\
\hline
\end{tabular}

que não foram explicitados no Quadro. Não parece útil resumir toda essa seqüência de ações em uma ou duas "palavras-resumo" do tipo "ensinar", "ações do professor", "realizar ensino", "interação professor-aluno" etc. Buscar maior visibilidade é andar na direção contrária daquela de um discurso vago, genérico, de senso-comum. O Quadro 7 é, nesse sentido, ainda incompleto. Seria melhor representar a seqüência completa de comportamentos que constitui o "ensinar", explicitando, em cada elo da cadeia, os aspectos de cada um dos três componentes do comportamento (de cada relação com o meio) que constitui o "ensinar".

À direita do Quadro 7, nesse mesmo sentido, há apenas a explicitação das características do produto final do "ensinar" (da cadeia de comportamentos completa que constitui o "ensinar"). Não estão especificados os "produtos" intermediários, resultantes de cada elo da cadeia de comportamentos em exame. A disparidade da descrição de cada uma das colunas é tecnicamente incorreta (pelo menos do ponto de vista do que é analisar um comportamento complexo), só se justificando, aqui neste texto, por ser um primeiro momento de elucidação sobre um possível "conceito comportamental de ensinar". "Conceito comportamental" entendido como uma definição que explicita os componentes envolvidos em um comportamento, caracterizando a relação entre o que um organismo faz e o ambiente em que o faz. Essa está sendo a compreensão do conceito quando é examinada a noção de uma possível cadeia de comportamentos denominada "ensinar". Delinear com clareza e precisão todos os componentes de cada um dos elos dessa cadeia é, ainda, uma tarefa a ser feita com pesquisa cuidadosa e um razoavelmente extenso e detalhado trabalho artesanal de descrição.

Com o exame apresentado em relação aos Quadros 1 a 7, fica mais claro porque há uma estreita ligação entre "ensinar" e "aprender" e como se dá a relação de interdependência entre essas duas classes de fenômenos. Também fica mais claro porque e como elas se relacionam com "objetivos de ensino" (ou comportamentos-objetivo, como parece ser mais apropriado). Se os comportamentos-objetivo definem o que deve ser "aprendido", eles são o foco de análise desses dois eventos. São, também, o elo de ligação mais importante entre "ensinar" e "aprender". 
A análise apresentada ainda permite muitas questões. Algumas delas referem-se a controvérsias importantes, outras talvez possam revelar preconceitos, desconhecimento ou desinformação, simplismo ou ingenuidade sobre o que foi examinado. Tais possibilidades de questões, porém, não são consideradas impertinências ou dificuldades e sim um caminho a percorrer. Qualquer exame que as responda melhor do que a análise apresentada será bem vinda. O problema maior talvez esteja exatamente nos referenciais sobre o que considerar "melhor". Para os objetivos deste texto, o critério é o de visibilidade: quanto mais uma maneira de falar permitir enxergar o fenômeno de forma a permitir lidar com ele com eficácia e precisão, mais poderá ser considerado "melhor". Um exame mais detalhado do papel do conhecimento no processo de ensinar pode ajudar um pouco mais no esclarecimento - e, talvez, localização - desses dois processos e da relação entre eles.

\section{O CONHECIMENTO COMO CONDIÇÃO PARA O TRABALHO COM EDUCACÃO}

A possibilidade de intervenção na Educação ou por meio dela necessita de informações ou de dados que forneçam boas indicações para a ação. Os trabalhos de Ribes (1976) e Iñesta $(1982)^{3}$ denunciam o pouco uso do conhecimento científico disponível nas intervenções profissionais e mesmo na formação dos profissionais que vão agir na sociedade. Há uma desnecessária e destrutiva separação entre conhecimento científico disponível e o que é feito nas ações que constituem as atividades profissionais. O que, sem dúvida, vale também para os profissionais da Educação.

A produção de conhecimento novo, a organização do conhecimento disponível para torná-lo mais acessível ou mesmo a pesquisa que produza conhecimentos a respeito do comportamento humano relacionado a descobertas científicas recentes parecem caminhos importantes no aumento, explicitação ou descoberta de alternativas para a atuação em Educação. Deles parecem derivar condições para viabilizar intervenções conseqüentes e socialmente significativas no próprio fazer da Educação (Paviani, 1991; Paviani e Botomé, 1993; Botomé 1993a; 1993b; Botomé, 1996).

Duran (1981) apresenta essa perspectiva para propor o estudo de interações verbais entre professor e aluno. As mesmas considerações, porém, parecem servir para uma maior variedade de estudos e investigações nas universidades e nas escolas da sociedade. Um dos tipos de variáveis que tem sido estudados e que interfere com o que é feito na escola e produzido a partir dela é o repertório do professor: as suas possibilidades (e capacidade!) de agir.

A "capacidade" do professor, aí entendida a natureza e extensão de seu repertório, necessária para influir adequadamente sobre um produto educacional final satisfatório, tem sido freqüentemente posta em xeque e o seu progressivo declínio nos últimos anos tem sido convincentemente atribuído a causas de ordem variada como baixos salários, falta de apoio à pesquisa, repressão político-ideológica sobre a instituição universitária, etc. Cada vez mais cresce a convicção de que o que o docente faz se distancia do que deveria fazer e a queda da qualidade do ensino tem sido um rótulo designativo dos efeitos dessas deficiências sobre a interação educativa e seu produto. A questão que fica, ao se enfocar esse ponto específico do ângulo até aqui proposto, é saber quais as possibilidades de reação da universidade, no âmbito acadêmico, a esse boicote institucional (Duran, 1981, p. 89).

O que o docente faz e o que deveria fazer é uma ampla - muito ampla - gama de comportamentos sobre os quais não há ainda conhecimento suficiente e acessível. Descobrir e propor esses comportamentos por meio da produção de conhecimento e desenvolvê-los por meio do sistema de ensino parece ser um caminho viável e promissor para chegar a "uma mais precisa definição dos agentes históricos e das formas de atuação suscetíveis de conduzir à mudança almejada" (Oliveira e Dominice, 1979, p. 136). Talvez seja esse o desafio importante para ser enfrentado e o caminho que pode levar a Educação a passar do âmbito do problema para o da solução das dificuldades que o País enfrenta. Sem mitos e exageros a respeito de seu papel na sociedade.

\section{O PAPEL DO CONHECIMENTO SOBRE O COMPORTAMENTO, EM EDUCAÇÃO}

Seja o que for que constitua o trabalho em Educação, ele será realizado (e constituído) por comportamentos das pessoas, dos agentes dessa Educação. O próprio comportamento

\footnotetext{
${ }^{3}$ As obras, embora sejam do mesmo autor, são apresentadas com nomes diferentes.
} 
pode ser objeto de conhecimento e, até os dias atuais, pode ser dito que ele tem sido pouco estudado e que é pouco conhecido pelos educadores. Os dois aspectos talvez mais importantes da Educação - trabalhar com comportamentos de alunos por meio dos comportamentos dos professores - parecem não ter sido suficientemente considerados nos exames e nas atividades relacionados à Educação. Talvez, nesse sentido, seja importante considerar isso tudo de maneira mais clara no exame do que pode ser feito em relação à educação no País.

Quando o ensino é elaborado, planejado e executado nas escolas, há um aspecto em comum a qualquer forma, tipo, nível ou profundidade da reflexão, planejamento ou execução desse ensino: é necessário partir de algum ponto para fazer qualquer uma dessas três atividades. Qual é esse ponto? Quanto de concordância existe em relação a ele? Como descobrir qual o melhor e mais significativo? Que tecnologia é necessária para que os professores o tenham claro e possam trabalhar a partir dele?

Um outro aspecto que parece ser consensual no ensino é que a Educação deveria habilitar as pessoas a agirem de maneira que, de suas ações, decorressem resultados definidos e significativos para as demais pessoas que compõem a comunidade onde vive cada um. A produção de benefícios (sejam eles idéias, produtos ou serviços), porém, exige que seja aprendido o fazer responsável pela produção desses benefícios. Botomé (1981) destaca, a esse respeito, que, para poder realizar um ensino voltado para uma efetiva atuação dos aprendizes nas situações onde irão viver, é necessário ter claro: (1) o que é necessário produzir como resultado das ações dos atuais aprendizes, quando estiverem "formados", (2) com que aspectos da realidade os aprendizes terão de lidar, quando estiverem "formados", para produzir esses resultados e (3) o que os aprendizes necessitarão estar aptos a fazer para lidar com esses aspectos da realidade de forma a produzirem resultados que sejam significativos para a própria vida e para os demais.

Mais concretamente, o ensino precisa ser planejado a partir da especificação do que é necessário produzir e com o que é preciso lidar (realidade com a qual o aluno tomará contato) para poder produzir esses "resultados de interesse". Só com essas duas informações (a situação resultante desejável e a situação existente da qual é necessário partir) é possível dizer qual o trabalho (as ações humanas) que será necessário para a produção desse resultado a partir dos aspectos concretos da realidade (situações) com os quaỉs a pessoa defrontarse-á ou com que precisará lidar. A noção de produção, nesse caso, é ampla. Não está restrita apenas ao que, usualmente, é considerado "produção", no sentido de "coisas", objetos, em um tipo de ensino "profissionalizante" ou "técnico". Os trabalhos científicos ou intelectuais, por exemplo, também produzem (no caso, conhecimento) benefícios que não podem ser considerados da mesma forma, como produtos de uso direto, imediato ou mecânico.

Quando é examinado o que é feito no ensino, porém, o ponto de partida usualmente encontrado ou utilizado para planejar e realizar o ensino é diferente. Botomé e colaboradores (1979) consideram duas propostas de "etapas no planejamento de condições de ensino", desenvolvendo uma delas em contraposição ao que denominam de "maneira usual" de planejar o ensino. No Quadro 8 é apresentado um esquema básico dos comportamentos considerados usuais (mais comuns e difundidos) ao planejar e realizar ensino. Mesmo quando os objetivos de ensino são apresentados sob a forma de comportamentos, é mantida essa seqüência de comportamentos. O que é feito, nesse caso, é meramente colocar "conteúdos" (ou classes de informações, consideradas como "conhecimento") tradicionais sob a forma de ações observáveis. Para Ribes (1976, p. 18-23), fazer isso é apenas "comportamentalizar conteúdos ou classes de informações" tradicionalmente conhecidos. Lidar com comportamento humano, ao definir objetivos de ensino, exige muito mais do que fazer o que esse autor chama de "comportamentalizar informações existentes nos livros".

Em um trabalho com docentes de Enfermagem, Botomé e col. (1979) chegaram a propor um esquema de etapas de decisões ou de comportamentos de quem planeja o ensino, alterando substancialmente o que está ilustrado no Quadro 8. No Quadro 9 é possível ver essa segunda seqüência de ações humanas para planejar e desenvolver ensino: o ponto de partida é bastante diferente do que é apresentado no Quadro 8 e, nesse caso, o conhecimento tem um papel de instrumento para desenvolver os comportamentos humanos (as aprendizagens) significativos para o aprendiz estar apto a lidar com as necessidades (situações) da comunidade onde vai inserir-se como profissional ou como pessoa.

Quadro 8: Etapas básicas (esquematicamente) dos comportamentos usualmente apresentados ao planejar e realizar ensino em escolas (adaptado de Botomé e col., 1979) 


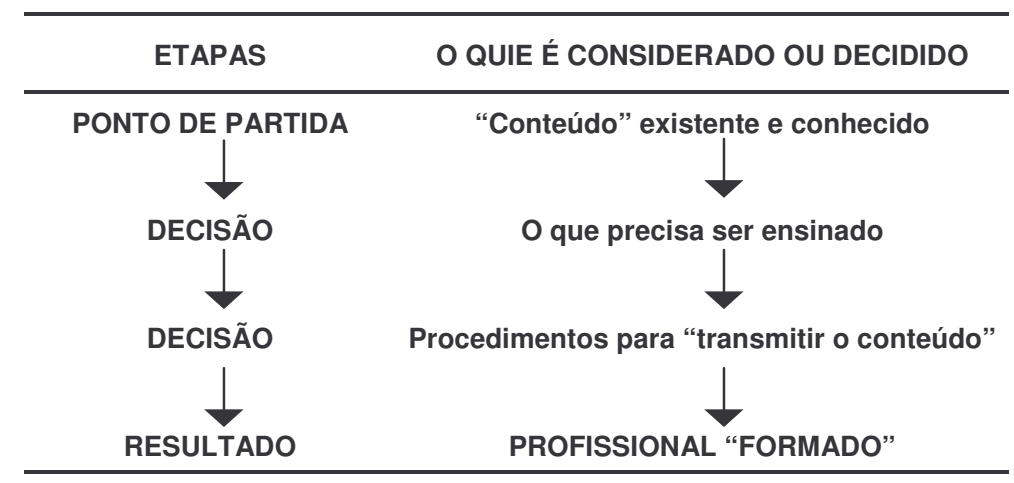

Comparando os Quadros 8 e 9, é possível ver que há caminhos diversos para chegar a "propor o que precisa ser aprendido pelos alunos" (Botomé, 1981). A ênfase predominante na literatura pertinente, em trabalhos considerados como "tecnologia educacional", parece ser, fundamentalmente, em "meios de ensino" (técnicas, recursos) e não em procedimentos para descobrir, definir e propor "o que ensinar". No Quadro 9, o "ponto de partida" dos exames e decisões de um docente não é o que "está nos livros", mas sim um "conhecimento da realidade". As "informações existentes" só aparecem como "instrumento" em um quarto momento de decisão. O esquema apresentado no Quadro 9 parece bem mais próximo de atender às considerações críticas de Nidelcoff (1974) sobre o "ensino livresco" ou sobre suas considerações sobre o papel da escola como instrumento de compreensão da realidade e para interferência nela ou, ainda, para sua construção (Nidelcoff, 1979); de Kaufman (1977a; 1977b), sobre a tendência dos sistemas educativos só se voltarem para o atendimento de "necessidades

Quadro 9: Etapas básicas de comportamento de docentes, descritas por Botomé e col. (1979), para caracterizar uma seqüência de ações do professor, ao planejar e realizar ensino

\begin{tabular}{cc}
\hline ETAPAS & O QUIE É CONSIDERADO OU DECIDIDO \\
\hline PONTO DE PARTIDA & O que a comunidade necessita? \\
DECISÃO & O que o profissional deve estar apto a \\
$\mid$ & - informações existem? \\
RESULTÁrio ensinar para o aluno & - informações produzir? \\
\hline & - outras condições?
\end{tabular}

internas" (os livros, o conhecimento etc.) e não enfatizarem "necessidades externas" ao próprio sistema educacional. Também o exame de Paulo Freire (1971), identificando mais "domesticação do que humanização" no ensino, e a análise de Holland (1978) a respeito de não haver trabalho com os determinantes dos problemas mas apenas com os efeitos que os caracterizam (no caso, lidar com a aprendizagem, e não com o que os professores fazem, corresponderia a lidar com os "efeitos" e não com as "causas"), são consistentes com o que está esquematizado no Quadro 9. Paviani (1991) faz uma análise sobre as relações entre realidade e Educação, mostrando o papel fundamental do processo de ensino para capacitar 
as pessoas a lidarem com sua realidade e não a lidarem apenas com noções desligadas de seu mundo concreto, embora tal mundo envolva sempre uma complexa rede conceitual.

O esquema apresentado no Quadro 9 ainda é geral e necessita de especificações e detalhamentos maiores. Como obter as informações em cada nível explicitado? Que tipo de informações são relevantes? Como lidar com elas? O que os docentes precisam aprender a fazer para mudar da maneira de trabalhar ilustrada no Quadro 8 para a que é apresentada no Quadro 9 ? O caminho apontado no esquema do Quadro 9 sugere a necessidade de "uma mais precisa definição dos agentes históricos e das formas de reação suscetíveis de conduzir à mudança almejada" (Oliveira e Dominice, 1979, p. 136) ou, como diz Duran (1981, p. 8-9), "a questão que fica (...) é saber quais as possibilidades de reação da universidade, no âmbito acadêmico, ao boicote institucional que sofre". Postman e Weingartner (1974) também apontam as controvérsias existentes nas práticas usuais e algumas possibilidades de ensino na mesma direção que é indicada pelo esquema do Quadro 9.

Com o conhecimento atualmente disponível é possível ir mais longe do que as considerações apresentadas pelos trabalhos que questionam o "modelo tradicional" de planejar (ou "pensar" como talvez preferissem alguns) e realizar o ensino (ver Quadro 8) e das críticas dos autores citados. Com o que é sintetizado no Quadro 9, como uma alternativa de encaminhamento, é possível perceber opções disponíveis a respeito das etapas de planejamento (ou de raciocínio) e de desenvolvimento do ensino que podem constituir novas bases para a construção de possíveis caminhos para o trabalho relacionado à tecnologia educacional.

Botomé (1981) explicita, com um trabalho a respeito da descoberta de comportamentos significativos e da proposição deles como objetivos de ensino, a possibilidade de avançar ainda mais nas etapas de trabalho ilustradas no Quadro 9. Essa proposta pode ser vista de maneira esquemática no Quadro 10, no qual é possível examinar uma seqüência de dez etapas que parecem fundamentais para viabilizar um ensino que atenda à "realidade social" e possa, de fato, ser considerado "algo importante ou prioritário para o País". As dez etapas permitem algumas percepções. Além de "parecer tornar viável" um outro processo para construir ou desenvolver ensino, fica claro que há um agente importante em todo o processo: 0 docente. Descobrir, ensinar e divulgar quais os comportamentos dos docentes que são importantes e necessários para tornar reais as dez etapas descritas no Quadro 10 parece ser um caminho para concretizá-las no ensino. Cada uma dessas etapas e os comportamentos relacionados a elas são um problema de pesquisa e exigem perguntas, procedimentos e maneiras de analisar e interpretar dados típicos (e novos, até!) da área de conhecimento relacionada ao estudo do comportamento (a Psicologia), conforme foi examinado e proposto por Botomé (1981).

Além dessas considerações, cada etapa do Quadro 10 é condição para a etapa seguinte tornar-se viável. A própria generalidade da descrição dessas etapas exige níveis de especificação ainda maiores, o que leva à exigência de definir melhor quais as áreas de pesquisa e de conhecimento relevantes para apoiar cada uma das múltiplas decisões envolvidas no processo de planejar e realizar o ensino.

Os itens na parte superior do Quadro 10 salientam a natureza e as atividades predominantes (mas não as únicas) nas etapas desse processo: decisão, pesquisa, resultado. Explicando um pouco, pela seqüência numerada à esquerda do Quadro 10, o ponto inicial não é o mesmo que aparecia no Quadro 8. O que era o ponto de partida no primeiro quadro corresponde à sétima etapa no esquema representado no Quadro 10. Em relação ao Quadro 9, a primeira etapa é detalhada em duas no Quadro 10: com que situações o aprendiz deverá lidar

Quadro 10: Etapas básicas (representadas em esquema) de comportamentos de docentes, apresentadas por Botomé (1981), para caracterizar uma seqüência (geral) de ações, ao planejar e realizar ensino

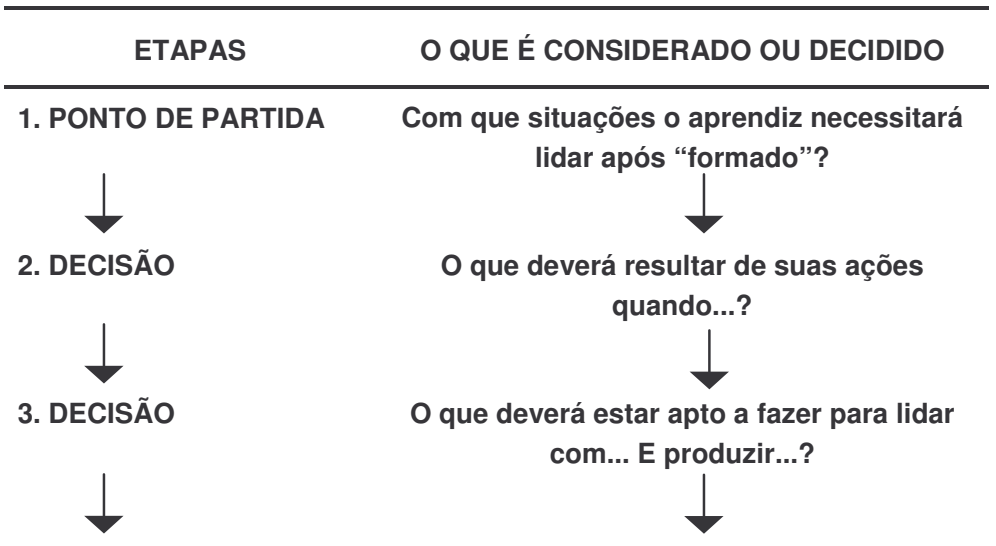




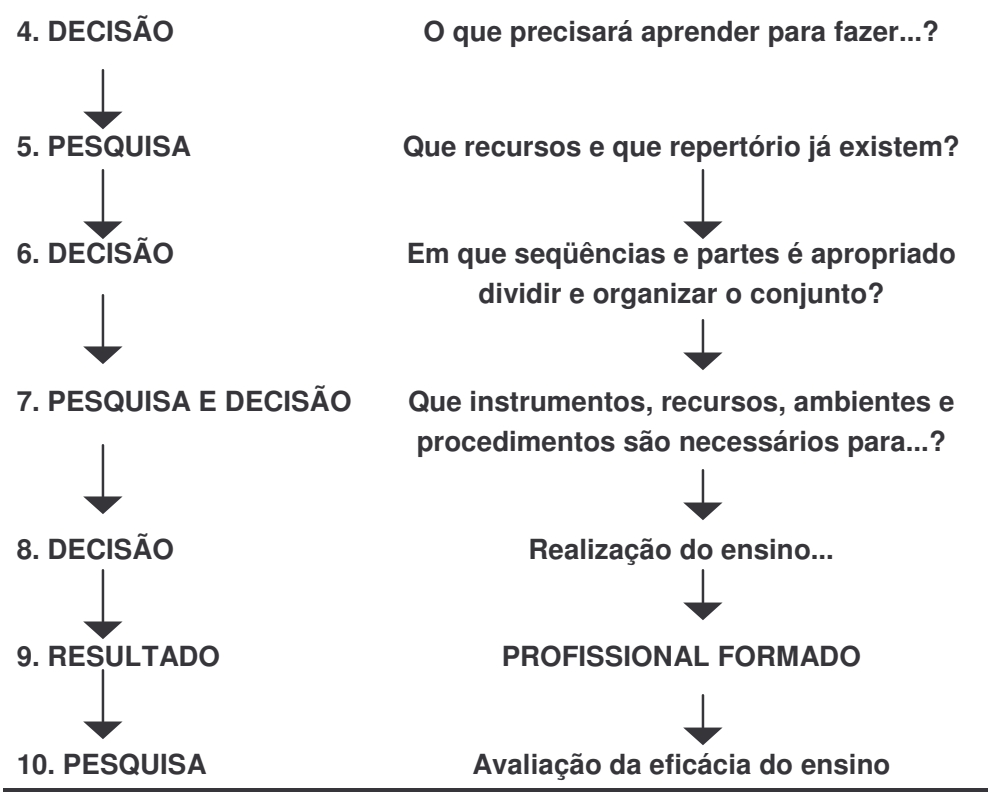

quando "formado" e o que deverá resultar de suas ações ao lidar com essas situações.

Esses são dois aspectos da "realidade" que, conhecidos (havendo dados a respeito deles), permitem uma outra decisão: que ações são apropriadas para que o profissional formado lide com as situações que encontra e que permitam produzir o que é significativo para atender às necessidades da população na área, região ou núcleo humano onde o profissional vai atuar. No Quadro 10, essa é a terceira etapa, enquanto era a segunda no Quadro 9 e nem sequer aparecia no Quadro 8. O tipo de raciocínio (e o padrão de conduta que o quadro apresenta) no primeiro esquema não leva em conta o comportamento humano como centro do ensino, nem parece considerá-lo como instrumento de transformação da realidade. É importante esclarecer aqui que a expressão "lidar" significa uma ampla gama de contatos com qualquer aspecto da situação na qual a pessoa age ou deverá agir. Desde o simples e genérico "tomar contato", até "atentar", "levar em conta" ou "agir em função de". "Contato" é uma expressão que diz respeito a qualquer um dos órgãos dos sentidos.

Tendo descrito esses três aspectos (três primeiras etapas), fica possível descobrir "o que o aluno necessita aprender para ser capaz de realizar as ações necessárias, de forma a lidar com as situações que encontrará e a produzir as transformações nessas situações que sejam significativas para a vida dos que dependem ou se relacionam com sua atividade profissional ou pessoal”. As demais etapas são necessárias para, gradualmente, poder tomar a decisão sobre os "meios de ensino" (etapa 7). Não é, porém, objetivo deste texto detalhar essas etapas todas.

Em síntese, o trabalho com ensino é, basicamente, constituído por uma interação entre professor e seus alunos. Essa interação não é algo sem definição ou impossível de ser vista ou tornar-se visível. O exame aqui feito, mostra um instrumental - a análise do comportamento - que possibilita uma grande visibilidade dos processos denominados de ensinar e de aprender. Uma cadeia composta por várias classes de comportamentos complexos, em uma seqüência articulada, de um organismo - o professor - definida por um resultado: uma interação entre duas classes de comportamentos (ou duas cadeias de classes de comportamentos) de um outro organismo - o aluno. A mudança na alteração da interação dos alunos com seus respectivos meio como resultado do trabalho de um professor, é o que indica que houve aprendizagem produzida por um ensino. Os dois conjuntos de Quadros, 1 a 7 e 8 a 10, representam, de certa forma, o mesmo exame do trabalho de ensinar. No primeiro conjunto foram evidenciados os componentes dos comportamentos que constituem o "ensinaraprender" e, no segundo, uma sequência de classes de respostas que constituem diferentes processos, conforme for o entendimento do que consistem "ensinar" e "aprender.

O exame que este texto exemplifica é um dos tipos de contribuição do trabalho dos que desenvolveram, com o ensino da professora Carolina M. Bori, ou a partir dele, uma das possibilidades de uso do conhecimento reunido sob o nome de Análise Experimental do Comportamento. Nesse caso, seu uso no ensino. As possibilidades de desenvolvimento dos 
conceitos e da tecnologia para o ensino, com a utilização dos recursos dessa maneira de analisar os fenômenos nos quais está envolvido o comportamento das pessoas, parecem promissoras. Tanto como avanço na eficácia e na visibilidade a respeito do que é feito em relação a eles, quanto nas possibilidades de ir em busca da relevância social do trabalho com ensino e com educação como Paulo Freire acentua em suas contribuições em torno de seu programa de ensino para alfabetizar adultos. Programa muito bem elaborado e que constitui uma das riquezas do País, ainda com muito por esclarecer e descobrir. Como programa, porém, já é uma preciosa descoberta que permite a um professor auxiliar a seus alunos a mudar sua relação com o meio de uma maneira extremamente eficaz; a mudar de relações de dominação para relações de maior equilíbrio nas relações de poder.

Foi triste o País não ter continuado, desde o começo da década de 1960, a desenvolver essas contribuições. Talvez ele estivesse com a educação de seus habitantes em condições muito diferentes, se essas contribuições tivessem sido examinadas, integradas e desenvolvidas com a isenção que merece um trabalho científico e de qualidade. Felizmente, é sempre possível retomar e corrigir o rumo que preconceitos, poderes arbitrários e condições ou "acidentes de percurso" impuseram ao ensino. Com seriedade, compromisso social, dedicação e preparação científica pode ser recuperado muito do que foi perdido.

\section{REFERÊNCIAS BIBLIOGRÁFICAS}

Bloom, B. S.; Englehart, M. D.; Furts, E. J.; Hill, W. H.; Krathwohl, D. R. (1956). A taxonomy of educational objetives: handbook I, the cognitive domain. New York: David Mc Kay, Co.

Bolles, R.C. (1970). Species-specific defense reactions and avoidance learning. Psychological Review, 77: $32-48$.

Botomé, S.P. (1981). Objetivos comportamentais no ensino: a contribuição da Análise Experimental do Comportamento. Tese de doutoramento. Universidade de São Paulo.

Botomé. S. P. (1993a). O problema de pesquisa em Ciência: características e origem como partes integrantes e definidoras do processo de fazer Ciência. Veritas, 38 (152), 625-633.

Botomé, S. P. (1993b). Metodologia de pesquisa: a lucidez orientando a ação. Em: T. R. S. Dias, F. E. Denari, O. M. Kubo, Temas em Educação Especial 2. São Carlos: Editora da Universidade Federal de São Carlos.

Botomé, S. P. (1996). Pesquisa alienada e ensino alienante: o equívoco da extensão universitária. Petrópolis: Ed. Vozes; São Carlos: Ed. da Universidade Federal de São Carlos; Caxias do Sul: Ed. da Universidade de Caxias do Sul.

Botomé, S. P.; Gonçalves, C. M. C.; Miranda, A. M. M.; Silva, E. B. N.; Cardoso, D. R.; Ubeda, E. M. L.; Silva, E.; Pedrazzani, J. C.; Naganuma, M.; Ogasawara, M.; De Rose, T. M. S.; Franco, W. (1979). Uma análise das condições necessárias para propor objetivos de ensino nas disciplinas do Curso de Enfermagem. Ciência e Cultura (Resumos), 31, 131.

Bushell, D. (1973). Classroom behavior: A little book for teachers. New Jersey: Prentice-Hall.

Catania, A. C. (1973). The concept of the operant in the analysis of behavior. Behaviorism, 1, 103-116.

Duran, A.P. (1981). Padrões de comunicação oral e compreensão da comunicação escrita na universidade: estudos no Nordeste. Tese de doutorado. São Paulo: Universidade de São Paulo.

Freire, P. (1968). La concepción "bancaria" de la Educación y la desumanización - la concepción bancaria de la Educacón y la humanización. Cristianismo y Sociedad (Suplemento - Edición no comercial). Montevideo: Junta Latino-Americana de Iglesia y Sociedad.

Freire, P.(1971). Extensão ou comunicação? Rio de Janeiro: Paz e Terra.

Freire, P. (1976). Uma educação para a liberdade. Rio de Janeiro: Paz e Terra.

Freire, P. (1977). Pedagogia do oprimido. Rio de janeiro: Paz e Terra.

Freitas, L. C. (1979). Programação de contingências em ambiente educacional: uma análise crítica. Trabalho apresentado no Simpósio sobre Programação de Ensino, promovido pela Associação de Modificação de Comportamento, na Universidade Federal de São Carlos. Não publicado.

Holland, J. G. (1978). To Cuba with the venceremos brigade. Behaviorists for Social Action Journal, 1, (1), 21-28.

Iñesta, E.R. (1982). El conductismo: reflexiones críticas. Barcelona: Ed. Fontanella.

Kaufman, R. A. (1977a). Evaluaciones de necesidades: internas e externas. Revista de Tecnologia Educativa. 1 (3), 84-91.

Kaufman, R. A. (1977b). Planificación de sistemas educativos. México: Ed. Trillas.

Keller, F. S. (1972). Adeus, Mestre! Ciência e Cultura, 24, (3), 207-217.

Kerbauy, R. R. (1983). (Org.). Fred Simmons Keller. São Paulo: Ática.

Mager, R. F. (1976). A formulação de objetivos de ensino. Porto Alegre: Ed. Globo.

Mager, R. F. (1977a). Análise de objetivos. Porto Alegre: Ed. Globo.

Mager, R. F. (1977b). Medindo os objetivos de ensino. Porto Alegre: Ed. Globo.

Mager, R. F. e Pipe, P. (1976). Análise de problemas de desempenho. Porto Alegre: Ed. Globo.

Mechner, F. (1974). Análise comportamental de tarefas. São Paulo: Fundação CENAFOR.

Nale, N. (1990). Programação de ensino no Brasil: o papel de Carolina Bori. Psicologia USP, 9(1), 275-301.

Nidelcoff, M. T. (1974). Maestro pueblo o maestro gendarme? Rosário (Argentina): Ed. Biblioteca.

Nidelcoff, M. T. (1979). A escola e a compreensão da realidade. São Paulo: Ed. Brasiliense. 
Oliveira, R. D. \& Dominice, P. (1979). O debate pedagógico. Em Z. Brandão (Org.), Democratização do Ensino: meta ou mito? Rio de Janeiro: Francisco Alves.

Parra, N. (1978). Tecnologia da Educação e o ensino superior - perspectivas. Educação Brasileira. 1, (2), 59-86.

Paviani, J. e Botomé, S.P. (1993). Interdisciplinaridade: disfunções conceituais e enganos acadêmicos. Caxias do Sul: Editora da Universidade de Caxias do Sul.

Paviani, J. (1991). Problemas de Filosofia da Educação. 6ª ed. Petrópolis: Ed. Vozes.

Pavlov, I. P. (1979). O reflexo condicionado. Em I. Pessoti (Org.), Pavlov. São Paulo: Ed. Ática.

Popham, W. J. \& Baker, E. L. (1976a). Como estabelecer metas de ensino. Porto Alegre: Ed. Globo.

Popham, W. J. \& Baker, E. L. (1976b). Sistematização do ensino. Porto Alegre: Ed. Globo.

Popham, W. J. \& Baker, E. L. (1976c). Como ampliar as dimensões dos objetivos de ensino. Porto Alegre: Ed. Globo.

Posner, G. J. \& Strike, K. A. (1975). Ideology versus technology: the bias of behavioral objectives. Educational Technology, May, 28-34.

Postman, N. \& Weingartner, C. (1974). Contestação: nova fórmula de ensino. Rio de Janeiro: Ed. Expressão e Cultura.

Ribes, E. (1976). Formación de profesionales e investigadores en Psicologia con base en objetivos definidos conductualmente. Enseñanza e Investigación en Psicologia. 1 (2), 18-23.

Schick, K. (1971). Operants. Journal of Experimental Analysis of Behavior. 15: 413-423.

Seligman, M. E. P. (1970). On the generality of the laws of learning. Psychological Review. 77, 406-218.

Sherman, J. G. \& Ruskin, R. S. (1978). The Personalized System of Instruction. New Jersey: Educational Technology Publications.

Skinner, B. F. (1931). The concept of the reflex in the descriptions of behavior. Journal of General Psychology. 5, 427-458.

Skinner, B. F. (1935). The generic nature of the concepts of stimulus ande response. Journal of General Psychology. 12, 40-65.

Skinner, B. F. (1938). The behavior of organisms. New York: D. Appleton-Century.

Skinner, B. F. (1957). Verbal behavior. New York: Appleton-Century-Crofts.

Skinner, B. F. (1969). Contingencies of reinforcement. New York: Appleton-Century-Crofts.

Skinner, B. F. (1972). Tecnologia do ensino. São Paulo: Editora Herder e Editora da Universidade de São Paulo.

Skinner, B.F. (1974). Ciência e comportamento humano. São Paulo: EDART e Editora da Universidade de São Paulo.

Staddon, J. E. R. (1967). Asymptotic behavior: the concept of the operant. Psychological Review. 5, (74), $377-391$.

Steves, O. P. (1968). Objetivos educacionais. Rio de Janeiro: Arte e Indústria Editora.

Vargas, J. S. (1974). Como formular objetivos de ensino úteis. São Paulo: Ed. Pedagógica e Universitária.

Wheeler, A. H. \& Fox, W. L. (1973). Modificação de comportamento: guia do professor para a formulação de objetivos instrucionais. São Paulo: Ed. Pedagógica e Universitária. 